\title{
APLICAÇÃO DA METODOLOGIA DE SUPERFÍCIE DE RESPOSTA NO ESTUDO DA PRODUÇÃO DE PECTINASE POR FERMENTAÇÃO EM ESTADO SÓLIDO DO PEDÚNCULO DE CAJU
}

\author{
Sharline Florentino de Melo Santos ${ }^{1}$, Rosane Liege Alves de Souza ${ }^{2}$, Siumara R. \\ Alcântara ${ }^{3}$, Gustavo Adolfo Saavedra Pinto ${ }^{4}$, Flávio Luiz Honorato da Silva ${ }^{5}$, Gorete \\ Ribeiro de Macedo ${ }^{6}$
}

\begin{abstract}
RESUMO
As enzimas pectinolíticas são usadas na extração de suco de fruta e sua clarificação, tratamento de fibra têxtil e extração de óleo vegetal. O objetivo deste trabalho foi utilizar a metodologia do planejamento experimental fatorial e análise de superfície de resposta para verificar os efeitos da umidade inicial do meio, adição de sulfato de amônia e de fosfato de potássio na produção da poligalacturonase através da fermentação em estado sólido, usando como substrato o resíduo do pedúnculo de caju seco (Anacardium occidentale L.) e como agente da fermentação o microrganismo Aspergillus niger CCT0916. A melhor condição de produção da poligalacturonase foi com umidade de $40 \%, 1 \%$ de sulfato de amônia e sem adição do fosfato de potássio atingindo-se uma atividade da poligalacturonase de $16 \mathrm{U} / \mathrm{g}$ e $82 \%$ de redução de viscosidade com 30 horas de fermentação.
\end{abstract}

Palavras-chave: Poligalacturonase, pectinases, fermentação em estado sólido, pedúnculo de caju, superfície de resposta.

\section{APPLICATION OF RESPONSE SURFACE METHODOLOGY IN THE STUDY OF PECTINASE PRODUCTION BY SOLID-STATE FERMENTATION OF THE CASHEW}

\begin{abstract}
Pectinolytic enzymes are used the in fruit juice extraction and its purification, textile fiber treatment and vegetal oil extraction. The aim of this work was to use the methodology of the factorial experimental design and response surface analysis to verify the effects of medium initial moisture content, addition of ammonium sulphate and potassium phosphate in the production of the polygalacturonase through of the solid-state fermentation, using cashew (Anacardium occidentale L.) as substrate and Aspergillus niger CCT0916 as transformation agent in the solid-state fermentation process. The best production condition of the polygalacturonase was at moisture of $40 \%, 1 \%$ of ammonium sulphate and without addition of the potassium phosphate. It was reached $16 \mathrm{U} / \mathrm{g}$ of activity of the poligalacturonase and $82 \%$ of viscosity reduction with 30 hours of fermentation.
\end{abstract}

Keywords: Polygalacturonase, pectinase, solid-state fermentation, cashew, response surface

\footnotetext{
1- Doutoranda em Engenharia Química, PPGEQ/UFRN - Natal- RN - Email: sharline @eq.ufrn.br

2- Mestranda em Engenharia Química, UAEQ/LEB/UFCG - Campina Grande - PB - Email:

3- Mestranda em Engenharia Agrícola, CTRN/LEB/UFCG - Campina Grande - PB- Email: syu.alcantara @ gmail.com

4- Pesquisador III da Embrapa Agroindústria TropicalCentro Nacional de Pesqui sa de Agroindústria Tropical, Laboratório de Bioprocessos Rua Dra. Sara Mesquita, 2270. Pici, 60511-110 - Fortaleza, CE - Brasil - Caixa-Postal: 3761, Telefone: (85) 32991811 Fax: (85) 32991833, email: gustavo@ cnpat embrapa.br

5-Professor Dr. da Unidade Acadêmica de Engenharia Química, UFCG, Av. Aprígio Veloso 882 CEP 58.109-970, Campina Grande, Paraíba, Email:flavioluizh@yahoo.com.br

6-Prof. Dra. do Departamento de Engenharia Química, UFRN, Universidade Federal do Rio Grande do Norte. PPGEQ-NT-Campus Universitário-UFRN, Lagoa Nova, 59072-970 - NATAL, RN - Brasil, Telefone: (084) 2153769 Ramal: 229 Fax: (084) 2153770. Email: gomacedo@eq ufrn.br
} 


\section{INTRODUÇÃO}

As enzimas pectinolíticas ou pectinases hidrolisam as substâncias pécticas sob diferentes mecanismos de reação, substrato preferencial e padrões de ação. Elas são classificadas em pectinoesterase, que promove a desesterificação da cadeia de pectina, e despolimerase que são responsáveis pela quebra desta cadeia. Das despolimerase a poligalacturonase é a enzima com função hidrolítica principal. Para maioria dos usos industrial, as poligalacturonases produzidas por fungo provam ser útil pela alta atividade e atividade ótima em faixa de $\mathrm{pH}$ baixa servindo para grande parte das aplicações em processos com frutas e vegetais (Zheng \& Shetty, 2000).

Algumas das aplicações destas enzimas nas indústrias de alimentos incluem amadurecimento de frutas, clarificação e redução de viscosidade em sucos de frutas, tratamento preliminar do suco de uva para indústrias vinículas, extração de polpa de tomate, fermentação de chá e chocolate, tratamento de resíduos vegetias, desengomagem de fibras nas indústrias têxtil e de papel, nutrição animal, enriquecimento protéico de alimentos infantis e extração de óleos (Uenojo \& Pastore, 2007).

Diversas companhias na Europa, Estados Unidos e Japão produzem pectinases e preparações comerciais de pectinases (Gummadi \& Panda, 2003). Atualmente, essas enzimas correspondem a cerca de $25 \%$ do mercado mundial de enzimas (Jayani et al., 2005). O valor estimado de vendas de pectinases em 1995 foi de US\$ 1 bilhão (Kashyap et al. 1995).

Com relação às técnicas de fermentação, a fermentação em estado sólido geralmente é preferida por permitir a produção de enzimas brutas mais concentradas e, conseqüentemente, com menores custos de extração e purificação. Substratos típicos são resíduos agroindustriais, como casca de frutas cítricas, bagaço de beterraba doce e farelo de trigo (Silva et al., 2005).

A produção de pedúnculos de caju no Brasil é estimada em torno de 1,8 milhão de toneladas/ano concentrando-se basicamente na região Nordeste e com aproveitamento industrial, de apenas $15 \%$ do total (Kiss, 2005). A quantidade desperdiçada apresenta elevada concentração de nutrientes que têm potencial de uso para conversão por microrganismos, na obtenção de produtos de alto valor agregado como enzimas.
A maior parte dos microrganismos pectinolíticos produz um complexo de enzimas pectinolíticas. Fungos são geralmente usados como fonte das preparações comercial. Aspergillus e Rhizopus são espécies freqüentemente usadas pela alta atividade pectinolítica exibida dos membros gerados (Fawole \& Odunfa, 2003).

A produção de pectinases por microrganismos é influenciada pelas condições de cultivo, em particular da umidade do meio de cultura, tipo e concentração da fonte de carbono e nitrogênio, temperatura do cultivo, além de outros fatores.

O objetivo deste trabalho foi utilizar a metodologia do planejamento experimental fatorial e análise de superfície de resposta para verificar as influências das variáveis umidade inicial do meio, adição de sulfato de amônia e de fosfato de potássio no estudo da produção da poligalacturonase através da fermentação em estado sólido, usando como substrato o pedúnculo de caju seco e como agente da fermentação o microrganismo Aspergillus niger CCT0916.

\section{MATERIAL E MÉTODOS}

\section{Microrganismo}

O microrganismo empregado foi o Aspergillus niger CCT 0916, cedido pela Embrapa Agroindústria Tropical, com sede em Fortaleza-CE. Os esporos da linhagem foram preservados em tubos de ensaio com tampas rosqueadas contento solo estéril e estocados a $18{ }^{\circ} \mathrm{C}$

\section{Inóculo}

O microrganismo foi ativado em duas etapas de transferência, usando um meio básico conforme Couri (1993), composto por pectina cítrica $(10 \mathrm{~g} / \mathrm{L}), \mathrm{NaNO}_{3}(3 \mathrm{~g} / \mathrm{L}), \mathrm{KH}_{2} \mathrm{PO}_{4}(1$ $\mathrm{g} / \mathrm{L}), \quad \mathrm{MgSO}_{4} \quad(0,5 \mathrm{~g} / \mathrm{L}), \quad \mathrm{KCl} \quad(0,5 \mathrm{~g} / \mathrm{L})$, $\mathrm{FeSO}_{4} 7 \mathrm{H}_{2} \mathrm{O}(0,01 \mathrm{~g} / \mathrm{L})$ e Agar-agar $(20 \mathrm{~g} / \mathrm{L})$. O meio foi esterilizado por 20 minutos a $0,5 \mathrm{~atm}$.

Os esporos foram transferidos dos tubos com solo para o meio e incubados por cinco dias em estufa a $30^{\circ} \mathrm{C}$, constituindo o primeiro repique. $\mathrm{O}$ segundo repique foi obtido de modo semelhante ao primeiro, partindo dos esporos de primeiro repique.

Os esporos de segundo repique foram utilizados para obtenção de grande quantidade de esporos no meio de sabugo de milho. Cada repique pode ser mantido sob refrigeração por 
um período de quatro meses. Segundo este procedimento cada tubo de ensaio contendo o microrganismo no solo só deve ser usado 4 ou 5 vezes e descartado (Couri, 1993).

No frasco de sabugo com esporos foi adicionada uma solução $0,3 \% \mathrm{v} / \mathrm{v}$ de Tween. Após agitação vigorosa os esporos foram transferidos para Erlenmeyer com auxílio de gaze estéril. A quantificação da suspensão obtida foi feita através de contagem dos esporos em Câmara de Neubauer espelhada. O volume de suspensão de esporos adicionado ao meio de fermentação foi ajustado de modo a ter-se um inóculo de $10^{7}$ esporos por grama de substrato sólido.

\section{Meio de cultivo}

Como meio de cultivo utilizou-se o resíduo do pedúnculo de caju. $\mathrm{O}$ resíduo foi obtido a partir do pedúnculo de caju adquirido no comércio local da cidade de Campina GrandePB. Os frutos estavam maduros e apresentavam coloração vermelha.

Os cajus foram lavados em água corrente, e depois se fez a separação pedúnculo da castanha. O pedúnculo limpo foi triturado e peneirado para separação do suco. $\mathrm{O}$ bagaço úmido foi disposto em bandejas de alumínio cobertas com polietileno e levados a estufa com circulação de ar a temperatura de $60^{\circ} \mathrm{C}$ por um período de 30 horas em camadas de aproximadamente $0,5 \mathrm{~cm}$, para chegar-se ao resíduo seco do pedúnculo.

Os resíduos secos obtidos foram triturados em moinho de facas da marca TECNAL e armazenados em sacos de polietileno a temperatura ambiente. As análises químicas indicam que o resíduo seco do pedúnculo de caju possui: $7,7 \%$ umidade, $2,05 \%$ cinzas, $6,83 \%$ proteína, $35,45 \%$ de açúcares redutores (AR), $7,31 \%$ pectina e $\mathrm{pH}$ de 4,15 (Santos, 2005).

\section{Planejamento experimental}

Com o objetivo de verificar a influência das variáveis: concentração inicial de umidade, suplementação com uma fonte de nitrogênio e suplementação com uma fonte de fósforo na produção de pectinases foi elaborado um planejamento experimental fatorial $2^{3}$ com três repetições no ponto central, como mostra a Tabela 1.
Tabela 1- Matriz do planejamento fatorial $2^{3}$, com três repetições no ponto central.

\begin{tabular}{cccc}
\hline EXP & Umidade & $\mathbf{N}$ & $\mathbf{P}$ \\
\hline 1 & $-1(40)$ & $-1(0)$ & $-1(0)$ \\
2 & $+1(60)$ & $-1(0)$ & $-1(0)$ \\
3 & $-1(40)$ & $+1(1)$ & $-1(0)$ \\
4 & $+1(60)$ & $+1(1)$ & $-1(0)$ \\
5 & $-1(40)$ & $-1(0)$ & $+1(0,6)$ \\
6 & $+1(60)$ & $-1(0)$ & $+1(0,6)$ \\
7 & $-1(40)$ & $+1(1)$ & $+1(0,6)$ \\
8 & $+1(60)$ & $+1(1)$ & $+1(0,6)$ \\
9 & $0(50)$ & $0(0,5)$ & $0(0,3)$ \\
10 & $0(50)$ & $0(0,5)$ & $0(0,3)$ \\
11 & $0(50)$ & $0(0,5)$ & $0(0,3)$ \\
\hline
\end{tabular}

Como variáveis de resposta (dependentes) foram avaliadas a atividade poligalacturonásica (U/g), e o percentual de redução de viscosidade.

Os níveis das variáveis independentes utilizadas em ordem crescente $(-1,0,+1)$ foram $40 \%, 50 \%$ e $60 \%$ para umidade inicial, $0 \%$, $0,5 \%$ e $1,0 \%$ para nitrogênio e $0 \%, 0,3 \%$ e $0,6 \%$ para o fósforo. Como fonte de nitrogênio foi utilizado o sulfato de amônia P.A. da marca Vetec e como fonte de fósforo o fosfato de potássio monobásico P.A. da marca Vetec.

A umidade inicial do meio foi ajustada de acordo com a Equação 1 que informa o volume de água a ser utilizado em dez gramas de resíduo para obter a umidade desejada.

Volume água adicionado $=0,3779 \times$ (umidade desejada) - 10,388

\section{Processo fermentativo}

As fermentações foram realizadas em Erlenmeyer de $250 \mathrm{~mL}$ contendo 20 gramas do meio. Para garantir a uniformidade das amostragens o meio foi preparado, de acordo com a matriz do planejamento, em Beck de polipropileno e então distribuído nos Erlenmeyers. Os frascos foram tampados com tampão de algodão envolvido com gaze e autoclavados a $0,5 \mathrm{~atm}$ por 5 minutos.

Ao meio de fermentação frio foram inoculados $10^{7}$ esporos/grama de resíduo e incubados a $30^{\circ} \mathrm{C}$ em estufa úmida. As amostras foram retiradas em períodos de tempo regular durante o processo para a extração do complexo enzimático e posterior realização das medidas de atividade. Para cada amostragem um Erlenmeyer era retirado da estufa, estando 
todos nas mesmas condições iniciais do processo.

\section{Extração da enzima}

A extração do complexo enzimático foi realizada adicionando-se $2,5 \mathrm{~mL} /$ grama de meio fermentado de tampão acetato $200 \mathrm{mM}$ pH 4,5. Após homogeneização as amostras foram deixadas por 1 hora em banho maria com controle de temperatura a $30^{\circ} \mathrm{C}$, depois foram filtradas. $\mathrm{O}$ filtrado foi estocado em freezer.

\section{Atividade pectinolítica}

A atividade do complexo pectinolítico foi dosada através do método viscosimétrico, conforme procedimento adotado por Castilho (1997).

Em tubos de ensaio contendo $10 \mathrm{~mL}$ de pectina cítrica $1 \% \mathrm{p} / \mathrm{v}$ preparada em tampão acetato de sódio $200 \mathrm{mM} \mathrm{pH} \mathrm{4,5;} \mathrm{adicionou-se}$ $1 \mathrm{~mL}$ do extrato enzimático prosseguindo a reação por 10 minutos a $35^{\circ} \mathrm{C}$. Completado este tempo, ainda à mesma temperatura, a viscosidade da mistura reacional foi medida usando viscosímetro da marca "Schott", modelo 52013.

Foram realizados ensaios em branco, nos quais $1 \mathrm{~mL}$ de tampão acetato $200 \mathrm{mM}$ pH 4,5 foi adicionado à solução de pectina, ao invés do extrato enzimático. Com os valores da viscosidade do ensaio em branco e daquele com extrato enzimático, calculou-se a redução percentual de viscosidade devida à ação enzimática.

\section{Atividade da poligalacturonase}

A atividade poligalacturonásica do extrato enzimático foi baseada no aumento dos grupos redutores formados por ação da enzima. Em tubos de ensaio contendo $4 \mathrm{~mL}$ de solução de ácido poligalacturônico $0,25 \% \mathrm{p} / \mathrm{v}$ preparada em tampão acetato 200mM pH 4,5; previamente aclimatado a $35^{\circ} \mathrm{C}$, adicionou-se $0,25 \mathrm{~mL}$ de extrato enzimático, prosseguindo a reação enzimática por 30 minutos a $35^{\circ} \mathrm{C}$. Terminada a reação, transferiu-se $0,25 \mathrm{~mL}$ da mistura reacional para tubos de ensaio contendo $1 \mathrm{~mL}$ do reagente de DNS, após homogeneização adicionou-se $0,75 \mathrm{~mL}$ de água destilada e seguiu-se o procedimento para análise dos grupos redutores pelo método do DNS.
Os ensaios foram feitos em duplicatas, nos ensaios em branco (também em duplicata), a enzima foi adicionada ao ácido poligalacturônico e imediatamente transferida para os tubos contendo o DNS. A curva padrão foi feita com solução de ácido galacturônico na faixa de 0 a $1 \mathrm{mg} / \mathrm{mL}$.

Uma unidade de atividade corresponde à quantidade de enzima que libera 1 mol de ácido galacturônico por minuto de reação, nas condições de reação. Os resultados foram expressos em unidades de atividade por grama de meio fermentado (U/g).

\section{RESULTADOS E DISCUSSÃO}

Utilizando a ferramenta de planejamento experimental e análise de superfície de resposta é possível investigar a influência de determinadas variáveis em um processo e a forma de interação entre estas variáveis, bem como obter o valor das variáveis que maximizem os resultados esperados.

As Tabelas 2 e 3 mostram respectivamente os resultados experimentais da atividade poligalacturonásica e do percentual de redução de viscosidade quando se faz variar os fatores concentração inicial de umidade (U), a adição de uma fonte de nitrogênio $(\mathrm{N})$ e a adição de uma fonte de fósforo $(\mathrm{P})$. Os resultados estão apresentados para cada tempo de fermentação analisado.

Tabela 2 - Resultado experimental em termos de atividade poligalacturonásica

\begin{tabular}{ccccccc}
\hline \multicolumn{6}{c}{ Atividade PG por horas de fermentação } \\
\hline Exp. & $\mathbf{7}$ & $\mathbf{2 2}$ & $\mathbf{3 0}$ & $\mathbf{4 6}$ & $\mathbf{5 4}$ & $\mathbf{7 0}$ \\
\hline 1 & 0,0 & 0,0 & 1,7 & 3,0 & 3,1 & 2,1 \\
2 & 0,0 & 0,0 & 0,0 & 0,0 & 0,2 & 0,5 \\
3 & 1,7 & 4,9 & 16 & 4,7 & 1,8 & 0,1 \\
4 & 0,0 & 0,4 & 0,2 & 0,0 & 0,0 & 0,0 \\
5 & 1,8 & 11,6 & 3,2 & 1,3 & 3,5 & 1,8 \\
6 & 0,0 & 0,0 & 0,0 & 1,2 & 0,9 & 0,0 \\
7 & 0,0 & 11,9 & 0,0 & 1,7 & 0,0 & 0,3 \\
8 & 0,0 & 0,0 & 0,5 & 0,2 & 0,1 & 0,3 \\
9 & 0,0 & 2,6 & 1,1 & 1,3 & 0,3 & 0,2 \\
10 & 0,0 & 3,7 & 1,2 & 0,0 & 0,0 & 0,0 \\
11 & 0,0 & 3,2 & 0,9 & 0,8 & 0,0 & 0,6 \\
\hline
\end{tabular}


Tabela 3 - Matriz do planejamento experimental e resultado experimental em termos do percentual de redução de viscosidade

\% Redução viscosidade/horas de fermentação

\begin{tabular}{ccccccc}
\hline Exp. & $\mathbf{7}$ & $\mathbf{2 2}$ & $\mathbf{3 0}$ & $\mathbf{4 6}$ & $\mathbf{5 4}$ & $\mathbf{7 0}$ \\
\hline 1 & 0 & 74 & 76 & 61 & 46 & 37 \\
2 & 0 & 26 & 21 & 17 & 18 & 18 \\
3 & 0 & 72 & 82 & 69 & 43 & 31 \\
4 & 11 & 19 & 28 & 38 & 15 & 40 \\
5 & 1 & 70 & 74 & 63 & 52 & 38 \\
6 & 0 & 23 & 20 & 9 & 6 & 4 \\
7 & 0 & 61 & 73 & 59 & 43 & 21 \\
8 & 19 & 16 & 15 & 22 & 8 & 54 \\
9 & 0 & 46 & 38 & 30 & 19 & 13 \\
10 & 0 & 37 & 37 & 27 & 23 & 11 \\
11 & 0 & 32 & 37 & 38 & 24 & 36 \\
\hline
\end{tabular}

Com os resultados experimentais obtidos para cada hora de fermentação analisada, a partir do planejamento fatorial, é possível ajustar os dados para obter um modelo linear que relacione a atividade enzimática com os parâmetros estudados. É bom lembrar que os modelos obtidos são empíricos sendo aplicáveis apenas em uma determinada região.

De acordo com os dados experimentais os maiores valores de atividade enzimática são para 30 horas de fermentação. Assim, será apresentada a seguir a análise estatística detalhada para 30 horas de fermentação.

O modelo obtido para a atividade da poligalacturonase (PG) é apresentado pela Equação 3 e para o percentual de redução de viscosidade na Equação 4. Os coeficientes em negrito são os estatisticamente significativos ao nível de $95 \%$ de confiança.

$\mathrm{PG}(30 \mathrm{~h})=2,25-2,52 \mathrm{U}+1,48 \mathrm{~N}-1,77 \mathrm{P}-$ $1,30 \mathrm{UN}+1,85 \mathrm{UP}-2,15 \mathrm{NP}+2,23 \mathrm{UNP}$

$\mathrm{RV}(30 \mathrm{~h})=45,55-27,63 \mathrm{U}+0,88 \mathrm{~N}-3,13 \mathrm{P}-$ $0,38 \mathrm{UN}-0,38 \mathrm{UP}-2,38 \mathrm{NP}-0,63 \mathrm{UNP}$

O coeficiente de determinação ou explicação $R^{2}$ quantifica a qualidade do ajustamento, pois fornece uma medida da proporção da variação explicada pela equação de regressão em relação à variação total das respostas. Varia de 0 a $100 \%$ (Rodrigues \& Iemma, 2005).

$\mathrm{O}$ teste $\mathrm{F}$ apresenta a razão entre o $\mathrm{F}$ calculado e o $\mathrm{F}$ tabelado, sempre que esta relação for maior que um a regressão é estatisticamente significativa havendo relação entre as variáveis independentes e dependentes. Para que uma regressão seja não apenas estatisticamente significativa, mas também útil para fins preditivos, o valor da razão deve ser no mínimo maior que quatro (Barros Neto et al., 1996).

Neste caso o modelo apresentado na Equação 3 tem 97,3\% das variações obtidas explicadas pelo modelo e com um valor da razão de $\mathrm{F}_{\text {calculado }}$ por $\mathrm{F}_{\text {tabelado }}$ de 1,75 ; indicando que o modelo é estatisticamente significativo com 95\% de confiança (Barros Neto et al., 1996).

De acordo com o Diagrama de Pareto apresentado na Figura 1, para o modelo de atividade da poligalacturonase, à maioria dos efeitos são estatisticamente significativos ou estão bem próximos de $95 \%$ de confiança, neste caso a retirada de algum parâmetro não melhora a qualidade do ajuste, então se estudou o modelo com todos os parâmetros. A Tabela 4 apresenta a análise de variância para o modelo completo.

Tabela 4 - Análise de variância para atividade da poligalacturonase com 30 horas de fermentação

\begin{tabular}{lcccc}
\hline $\begin{array}{c}\text { Fonte } \\
\text { variação }\end{array}$ & SQ & GL & MQ & $\begin{array}{c}\text { Teste } \\
\text { F }\end{array}$ \\
\hline Regressão & 211,12 & 7 & 30,16 & 15,5 \\
Resíduo & 5,83 & 3 & 1,94 & \\
F.ajuste & 5,79 & 1 & & \\
Erro puro & 0,0434 & 2 & & \\
Total & 216,95 & 10 & & \\
\%R & 0,973 & & & \\
F tab. & 8,89 & & $\mathbf{F 5 \%}$ & 1,75 \\
\hline
\end{tabular}

Para o percentual de redução de viscosidade o Diagrama de Pareto (Figura 2) mostra que a única variável estatisticamente significativa é a umidade. Neste caso a retirada de alguns efeitos de menor valor contribui para um melhor ajuste do modelo.

O modelo com melhor ajuste é:

$$
\begin{aligned}
\mathrm{RV}(30 \mathrm{~h})= & 45,55-27,63 \mathrm{U}+0,88 \mathrm{~N}-3,13 \mathrm{P} \\
& -2,38 \mathrm{NP}
\end{aligned}
$$

A Tabela 5 apresenta a análise de variância para o percentual de redução de viscosidade com 30 horas de fermentação. Com o novo 
ajuste a razão de $\mathrm{F}_{\text {calculado }}$ por $\mathrm{F}_{\text {tabelado }}$ passa de 1,1 para 7,26 sendo agora o modelo não só estatisticamente significativo, mas também preditivo (Barros Neto et al., 1996), sem haver alterações no valor de $\mathrm{R}^{2}$, que era de $95,7 \%$ fica $95,6 \%$.

Tabela 5 - Análise de variância para percentual de redução de viscosidade com 30 horas de fermentação.

\begin{tabular}{lcccc}
\hline Fonte variação & SQ & GL & MQ & $\begin{array}{c}\text { Teste } \\
\text { F }\end{array}$ \\
\hline Regressão & 6234,50 & 4 & 1558,62 & 32,90 \\
Resíduo & 284,23 & 6 & 47,37 & \\
F.ajuste & 283,56 & 4 & & \\
Erro puro & 0,667 & 2 & & \\
Total & 6518,73 & 10 & & \\
\%R ${ }^{2}$ & 0,956 & & & \\
F tabl. & 4,53 & & $\mathbf{F 5 \%}=$ & 7,26
\end{tabular}

Como demonstra as Figuras 2 e 3 a umidade é o efeito de maior importância para o processo, estando com valor negativo, então o maior valor de atividade enzimática é atingida para os menores valores de umidade.

Com base nesta informação as superfícies de resposta forma construídas mantendo-se o valor de umidade fixa em $40 \%$, variando os valores das fontes de nitrogênio e fósforo. A superfície de resposta é a descrição gráfica do modelo, o que simplifica a interpretação dos resultados.

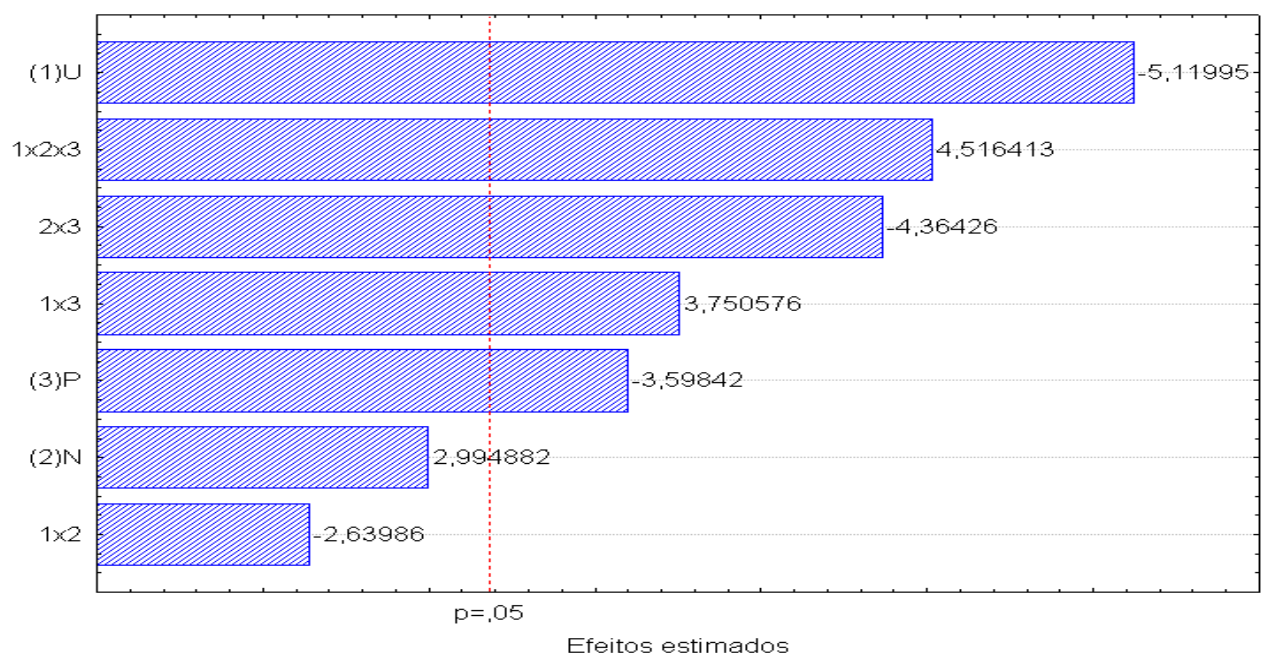

Figura 1 - Diagrama de Pareto para atividade da poligalacturonase.

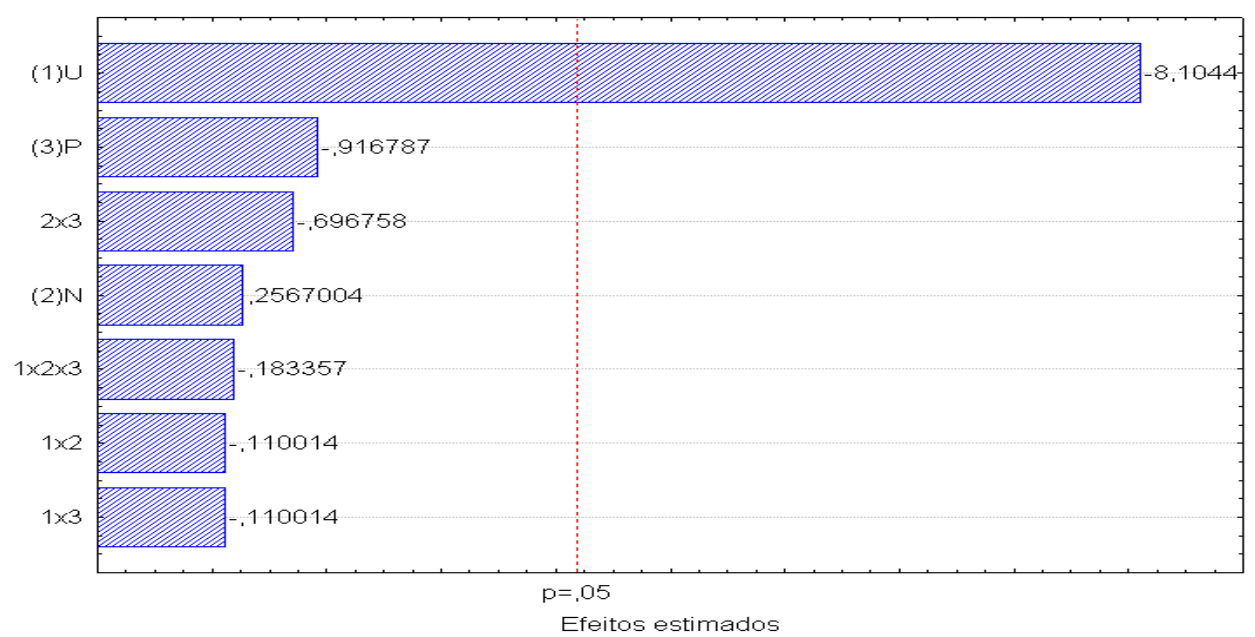

Figura 2 - Diagrama de Pareto para o percentual de redução de viscosidade. 
A Figura 3 apresenta a superfície construída a atividade da poligalacturonase. Nela observase que a máxima produção da poligalacturonase ocorre para valores de nitrogênio de $1 \%$ e de fósforo $0 \%$, sendo então de $15,55 \mathrm{U} / \mathrm{g}$. Este valor está próximo do valor experimental obtido nas mesmas condições que é de $16 \mathrm{U} / \mathrm{g}$.

Para o \% de redução de viscosidade a Figura 4 mostra que a adição das fontes de nitrogênio e fósforo têm pouca influência no processo, mantendo valores $\%$ de redução de viscosidade superior a $70 \%$ para quase toda faixa de valores estudadas, mantendo-se fixa a umidade em $40 \%$.

Assim como para atividade da poligalacturonase os maiores valores de $\%$ de redução de viscosidade são para valores de nitrogênio de $1 \%$ e sem adição da fonte de fósforo, com $40 \%$ de umidade chegando ao valor de $79,57 \%$ próximo do experimental que é de $82 \%$ de redução de viscosidade nas mesmas condições.

A adição das fontes de nitrogênio e fósforo tem efeitos semelhantes tanto para a máxima produção de poligalacturonase quanto para $o$ percentual máximo de redução de viscosidade, sendo que a adição de nitrogênio aumenta a produção de enzimas enquanto que a adição do fósforo é prejudicial.
De acordo com os resultados obtidos a concentração inicial de umidade é a variável de maior importância para o processo, estando sempre os maiores valores de atividade enzimática associada a baixos valores de umidade, $40 \%$. Este resultado é também citado por Botella et al. (2006) que estudou a influência da umidade inicial na produção de poligalacturonase usando resíduo da indústria de vinho (bagaço de uva), variando a umidade inicial de $45-80 \%$. Concluiu que a atividade enzimática decresce para valores de umidade superior a $65 \%$, atribuindo o fato ao decréscimo da porosidade, alterações na estrutura da partícula e baixa transferência de oxigênio.

A melhor condição de fermentação foi para 30 horas de processo com umidade de $40 \%$, nitrogênio $1 \%$ e sem necessidade da adição da fonte de fósforo com atividade da poligalacturonase de $15,55 \mathrm{U} / \mathrm{g}$ e $79,6 \%$ de redução de viscosidade. Este valor de atividade é superior aos citados na literatura para poligalacturonase obtida a partir de resíduos de frutas sendo $12 \mathrm{U} / \mathrm{g}$ para bagaço de laranja, 5 $\mathrm{U} / \mathrm{g}$ para casca de manga e 7,5 U/g para casca de banana usando Penicillium viridicatum $R F C 3$ com quatro dias de fermentação (Silva et al., 2002).

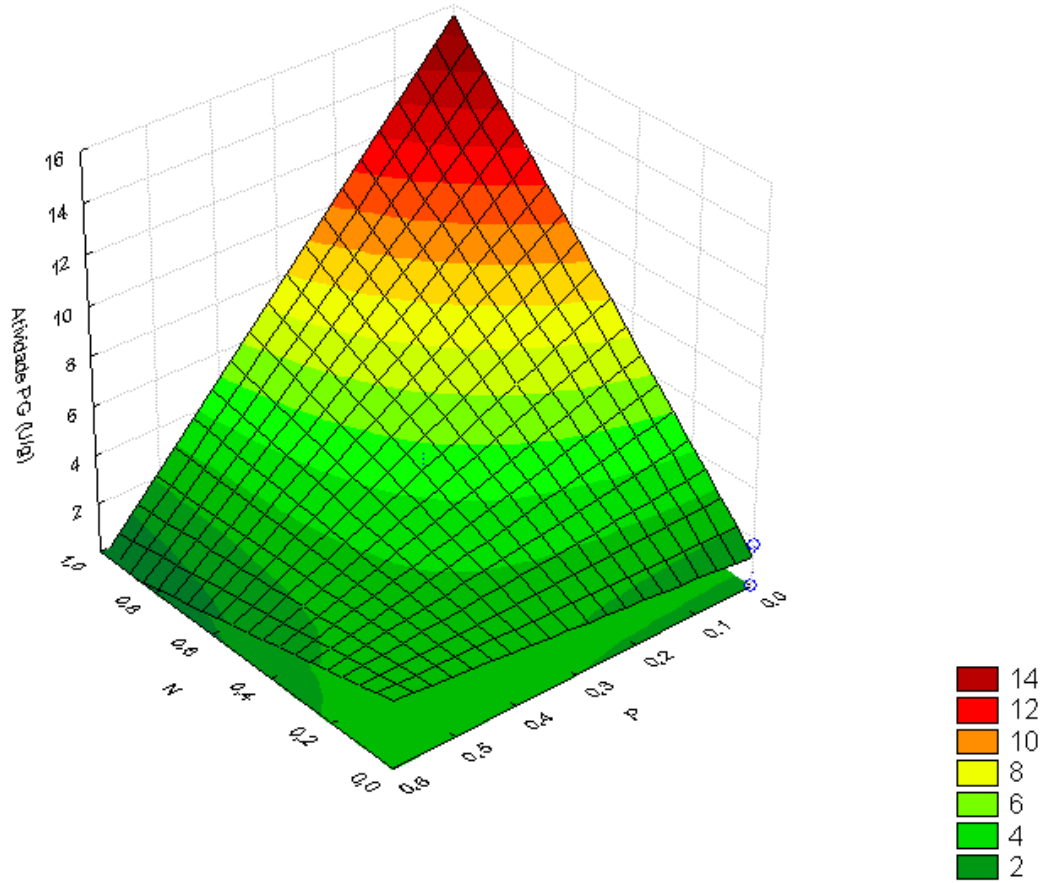

Figura 3 - Influência da adição das fontes de nitrogênio e fósforo na atividade da poligalacturonase para 30 horas de fermentação, fixando-se a umidade em $40 \%$ (-1). 


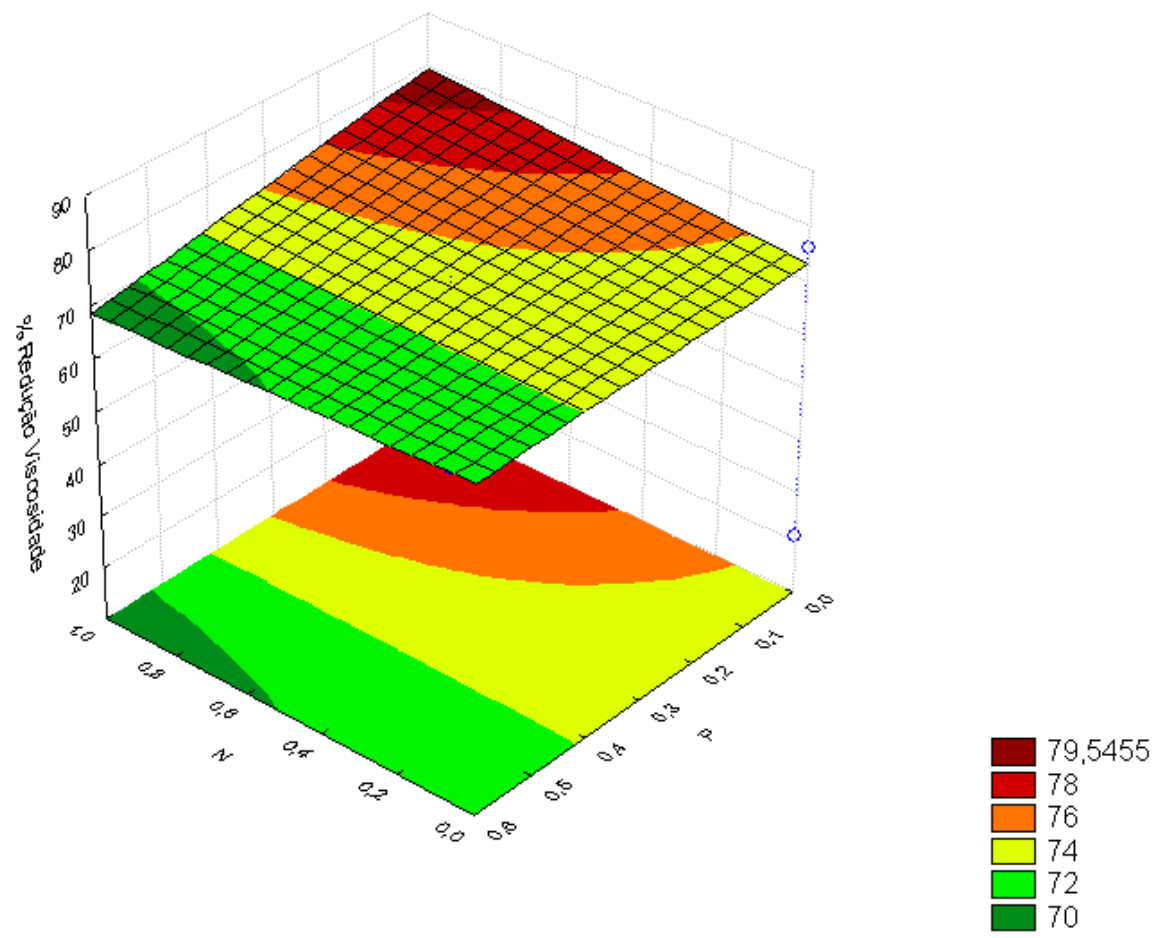

Figura 4 - Influência da adição das fontes de nitrogênio e fósforo no percentual de redução de viscosidade para umidade inicial de $40 \%$ com 30 horas de fermentação.

Zheng \& Shetty (2000) encontraram atividade de $29,4 \mathrm{U} / \mathrm{g}$ e $20,1 \mathrm{U} / \mathrm{g}$ para bagaço de morango e maçã, mas usando suplementação com ácido poligalacturônico, que encarece o processo, e estes valores foram obtidos após 40 dias de fermentação usando Lentinus edodes. Então em termos de produtividade $\mathrm{o}$ bagaço de caju ainda apresenta-se como melhor fonte produtora de pectinases a partir de resíduos de frutas.

\section{CONCLUSÕES}

O resíduo do pedúnculo de caju seco é uma fonte promissora de poligalacturonase. A melhor condição de fermentação foi com umidade inicial de $40 \%$, nitrogênio $1 \%$ e sem necessidade da adição da fonte de fósforo.

A umidade inicial do meio é a variável mais importante para o processo de produção de pectinases, estando os maiores valores de atividade associados a baixos valores de umidade do meio.

O maior pico de produção da enzima foi com 30 horas de processo. Os modelos obtidos para atividade da poligalacturonase e percentual de redução de viscosidade são estatisticamente significativos com atividade da poligalacturonase de $15,55 \mathrm{U} / \mathrm{g}$ e $79,6 \%$ de redução de viscosidade, valores próximos aos obtidos experimentalmente que foi de $16 \mathrm{U} / \mathrm{g}$ e $82 \%$ respectivamente.

\section{AGRADECIMENTOS}

Os autores expressam seus agradecimentos a CAPES e Embrapa Agroindústria Tropical (projeto 02.03.1.17) pelo auxílio financeiro.

\section{REFERÊNCIAS BIBLIOGRÁFICAS}

Barros Neto, B.; Scarminio, I.S.; Bruns, R.E. Planejamento e otimização de experimentos. $2^{\mathrm{a}}$ Ed. Campinas, SP: Editora da Unicamp, 1996, 299p.

Botella, C.; Diaz, A.; Ory, I.; Webb, C.; Blandino, A. Xilanase and pectinase production by Aspergillus awamori on grape pomace in solid state fermentation. Process Biochemistry, 2006.

Castilho, L.R. Recuperação de pectinases produzidas por Aspergillus niger em fermentação semi-sólida. Rio de Janeiro: COPPE/UFRJ, 1997. 96f. (Dissertação de Mestrado).

Couri, S. Efeito de cátions na morfologia do agregado e na produção de poligalacturonase por Aspergillus niger mutante 3T5B8. Rio de Janeiro: 
UFRJ/Escola de Química, Departamento de Engenharia Bioquímica, 1993. 199p. (Tese de Doutorado).

Fawole O.B., Odunfa S.A. Some factors affecting production of pectic enzymes by Aspergillus niger. International Biodeterioration \& Biodegradation, v.52, p.223-227, 2003.

Guammadi, S.N.; Panda, T. Purification and biochemical pro- perties of microbial pectinases - A review. Process Biochemistry. v.38, p.987-996, 2003.

Jayani R.S.; Saxena S.; Gupta, R. Microbial pectinolytic enzymes: A review. Process Biochemistry. v.40, p.2931-2944, 2005.

Kayshap, D.R.; Vohra, P.K.; Chopra, S.; Tewari, R. Applications of pectinases in the commercial sector: a review. Bioresour. Technol., v.77, n.3, p. 15-227, 2001.

Kiss, J. Reforma na casa. Revista Globo Rural. v233, p.58-63, 2005.

Rodrigues, M.I.; Iemma, A.F. Planejamento de experimentos e otimização de processos. $1^{a}$ Ed. Campinas, SP: Editora Casa do Pão, 2005. 326p.
Santos S.F.M.; Nobrega J.E.; Pinto G.A.S.; Silva F.L.H.; Macedo G.R. Caracterização do resíduo seco do pedúnculo de caju visando sua utilização como substrato para fermentação semi-sólida. In: XV Simpósio Brasileiro de Bioprocessos-SINAFRM, 15, 2005. Anais...CD Rom.

Silva, D.; Martins, E.S.; Silva, R.; Gomes, E. Pectinase production by Penicillium viridicatum RFC3 by solid state fermentation using agricultural wastes and agro-industrial by-products. Brazilian Journal of Microbiology. v.33, p.318-324, 2002.

Silva, D.; Tokuioshi, K.; Martins, E. S.; da Silva, R.; Gomes, E. Production of pectinase by solid-state fermentation with Penicillium viridicatum RFC3. Process Biochemistry, v.40, 2885-2889, 2005.

Uenojo, M.; Pastore, G.M. Pectinases: aplicações industriaias e perpectivas. Química Nova, v.30, n.2, 388-394, 1997.

Zheng Z.; Shetty, K. Solid state production of polygalacturonase by Lentinus edodes using fruit processing wastes. Process biochemistry. v.35, p.825-830, 2000. 


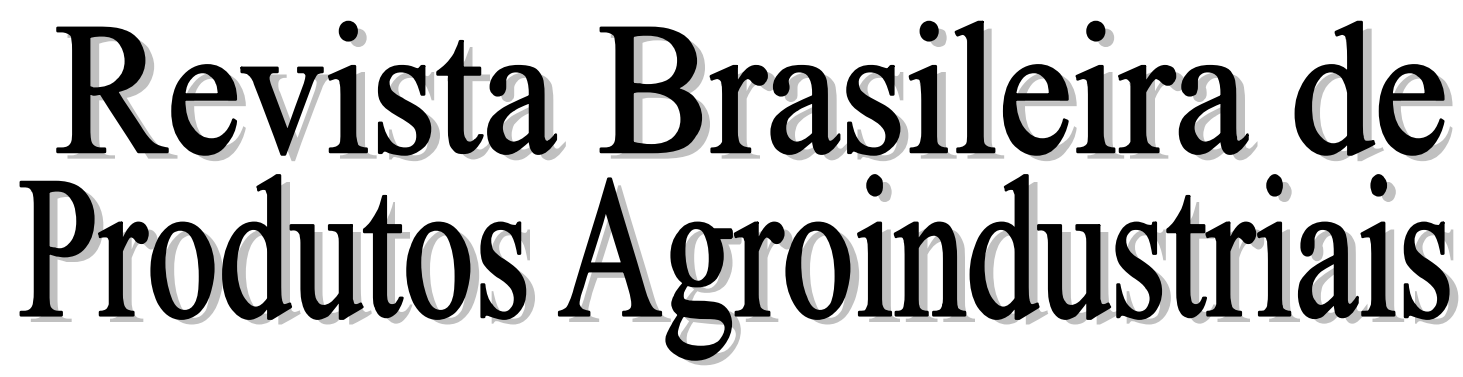

Brazilian Journal of

Agro-industrial Products 